\title{
KELIMPAHAN POPULASI PARASITOID Trichogramma sp DAN SERANGAN HAMA PENGGEREK BATANG PADI SAWAH DI KABUPATEN MINAHASA
}

\section{ABUNDANCE AND POPULATION PARASITOID Trichogramma sp STEM BORER PEST ATTACK IN RICE RICE DISTRICT MINAHASA}

\author{
R.T.D. Maramis, E. Senewe dan V.V. Memah \\ Jurusan Hama dan Penyakit Tumbuhan Fakultas Pertanian UNSRAT Manado_95115
}

\begin{abstract}
This research was aimed to identify morphological charactersofparasitoid Trichogramma sp. at each sampling location, to assess parasitoidsabundance, and to get attacking percentage data of rice stem borer. The sampling location is in Minahasa Region namely Tondano, Tompaso, Langoan and Kakas. The result revealed that adult size of the parasitoid was from 0.4 to 0.5 . The female antenna was mace with short and rare hair. The male parasitoid had straight antenna, and had a lot of hair.The total number of parasitoid Trichogramma spcollected from Langowan, Tompaso, Kakas, and Tondanowas 322. The abundance of parasitoid Trichogramma sp was different in each sampling location. The highest was collected in Langoan (115) followed by Kakas (86), Tompaso (64) and Tondano (57). Attacking percentage of rice stem borer wasvaried between sampling location. The average of attacking percentage on each location was 3,51\%. The highest of attacking percentage was Langowan (4.53\%) followed Kakas (4.24\%), Tompaso (3.40\%)and Tondano (2.27\%.)
\end{abstract}

Keywords: morphological, abundance parasitoid

\begin{abstract}
ABSTRAK
Tujuan penelitian ini adalah untuk mengetahui karakter morfologi parasitoid Trichogramma sp pada masing-masing lokasi pengambilan contoh, mengetahui kelimpahan parasitoid, dan mendapatkan data persentase serangan hama penggerek batang padi. Hasil identifikasi didapatkan tubuh serangga dewasa parasitoid berukuran $0,4-0,5 \mathrm{~cm}$, antenna betina berbentuk ganda, berbulu pendek dan tumbuh jarang, antenna jantan bentuk lurus dan banyak ditumbuhi bulu/ rambut-rambut. Hasil koleksi kelompok telur hama penggerek batang padi sawah di Wilayah Langowan, Tompaso, Kakas, dan Tondano muncul parasitoid Trichogramma sp. dengan total 322 parasit. Terdapat perbedaan kelimpahan parasitoid Trichogramma sp. yang ditemukan dimasing-masing lokasi studi. Kelimpahan populasi parasitoid tertinggi di wilayah Langowan (115), kemudian diikutio berturut-turut Kakas (86), Tompaso (64), dan Tondano (57). Persentase serangan hama penggerek batang padi sawah berfluktuasi dimasing-masing lokasi studi..Rata-rata persentase serangan pada keseluruhan lokasi pengamatan mencapai $3,51 \%$. Wilayah langowan merupakan persentase tertinggi serangan hama penggerek batang padi mencapai 4,53\%, diikuti berturut-turut Kakas 4,24\%, Tompaso 3,40\% dan terendah Tondano hanya 2,27\%.

Kata kunci: Morphologi, Parasitoid
\end{abstract}

Eugenia Volume 17 No. 1 April 2011 


\section{PENDAHULUAN}

Serangga hama yang menyerang tanaman padi sawah di Sulawsi Utara kurang lebih 20 jenis (Sembel, dkk. 2000). Dari sekian banyak hama yang menyerang tanaman padi sawah hanya beberapa yang tergolong penting dan merusak serta memberikan kerugian yang berarti, yakni hama penggerek batang padi sawah. Hama penggerek batang padi menyebar pada pertanaman padi sawah di Sulawesi Utara, dan terdapat 4 jenis hama penggerek batang yang menggrek tanaman padi sawah. Dari keempat jenis hama penggerek batang tersebut hanya satu menjadi dominan merusak tanaman padi sawah yakni S. innotata (Anonim, 2008; Sembel, dkk. 2000). Di Sulawesi Selatan hama utama tanaman padi sawah di antaranya hama penggerek batang padi sawah (Abdul dkk. 2010).

Pada umumnya pengendalian hama ini oleh petani di Sulawesi Utara masih sangat tergantung pada insektisida, namun belum memberikan hasil yang maksimal, karena serangan hama penggerek batang pada tahun $2007 \mathrm{di}$ Sulawesi Utara mencapai 1853,05 ha (Anonim, 2008). Saat ini hama penggerek padi sering mengacam tanaman padi sawah di Sulawesi Utara, diduga parasitoid yang mengontrol hama penggerek batang padi sawah mungkin densitas sudah mulai berkurang, tetapi di daerah lain hama penggerek batang padi sawah tidak memberikan kerugian, meskipun populasi hama tersebut ada di lapangan. Faktor yang belum menimbulkan kerugian pada tanaman padi tersebut disebabkan adanya peningkatan populasi parasitoid hama penggerek batang padi sawah.

Untuk menekan hama penggerek batang padi sawah perlu diterapkan pengendalian hayati dengan memanfaatkan parasitoid. Hawkins et al., (1997) mengemukakan, bahwa parasitoid merupakan bagian musuh alami yang banyak diteliti dan menunjukkan hasil yang baik dalam pengendalian serangga hama dibandingkan serangga predator. Di Indonesia parasitoid yang memarasit telur-telur hama penggerek batang padi sawah adalah Trichogramma japonicum, $T$. minitum, T. chailatracea, Telonomus sp.,
Tetrastichus schoenobii (Anonim, 1991; Kalshoven, 1991).

Di Sulawesi Utara, parasitoid Trichogramma sp. yang memarasit telur penggerek batang padi masih sebatas pada genus. Taroreh dkk. (1993) melaporkan, bahwa di Kecamatan Langowan telur-telur hama penggerek batang diparasit oleh parasitoid Trichogramma sp, Telenomus sp., dan Tetrastichus sp. Khusus untuk parasitoid Trichogramma sp menyebar pada pertanaman padi sawah di Kabupaten Minahasa yakni daerah dataran rendah Tumpaan 2.03 individu 5 ayunan ganda dan dataran tinggi Tondano dan Langowan 1,57 individu 10 kali ayunan ganda (Rondonuwu dan Rimbing, 2000) Jenis parasitoid Trichogramma sp yang ditemukan di Kabupaten Minahasa tidak diketahui memarasit serangga hama, karena parasitoid tersebut hanya ditemukan melalui penangkapan dengan jaring serangga.

Pelepasan parasitoid Trichogramma sp. selama 3 kali pada pertanaman padi sawah di Kabupaten Pinrang Sulawesi Selatan populasi parasitoid Trichogramma sp pada petak pelepasan 16,0 ekor sedang petak tanpa pelepasan parasitoid 6,00 ekor. (Melina dan Nurariaty, 1997). Data populasi parasitoid pada petak pelepasan parasitoid masih tergolong rendah, disebabkan jumlah imago parasitoid yang dilepas masih sangat kurang dan tidak diketahui jenis parasitoid Trichogramma sp yang ditinjau dari aspek morfologi. Peningkatan jumlah parasitoid yang akan di lepas di lapangan perlu mengetahui bioekologi parasitoid seperti kemampuan parasitoid memarasit inang di laboratorium dan memahami morfologi tentang parasitoid tersebut. Dengan mempelajari kebugaran parasitoid kita mampu menghasilkan parasitoid yang banyak untuk di lepas di lapangan. Bila terjadi peningkatan populasi parasitoid sudah tentu akan berdampak pada penurunan kerusakan tunas.pada tanaman padi sawah. Dari uraian tersebut di atas maka ditetapkan tujuan penelitian yakni mengetahui morfologi parasitoid Trichogramma sp, kelimpahan populasi dan persentase serangan hama penggerek batang padi. 


\section{METODE PENELITIAN}

\section{Tempat dan Waktu Penelitian}

Penelitian ini telah dilaksanakan di Kabupaten Minahasa dan kemudian dilanjutkan di Laboratorium Entomologi dan Hama Tumbuhan Fakultas Pertanian. Penelitian di laboratorium untuk mendapat data tentang parasitoid Trichogramma sp. Kegiatan penelitian ini memerlukan waktu selama 5 bulan.

\section{Metode}

\section{Penetapan Lokasi Penelitian}

Pertanaman padi sawah tersebar di beberapa Kecamatan Kabupaten Minahasa. Untuk lokasi penelitian sebagai tempat pengambilan contoh telur hama penggerek padi sawah adalah sebagai berikut : Kecamatan Langowan, Kecamatan Kakas, Kecamatan Tompaso, Kecamatan Tondano

\section{Pengambilan Contoh Telur}

Untuk mendapatkan specimen parasitoid telur Trichogramma sp pada hama penggerek batang padi sawah, maka setiap kecamatan diambil 4 lokasi. Ukuran contoh yang digunakan sebagai tempat pengambilan contoh telur penggerek batang padi adalah 0,2 ha per lokasi. Jadi jumlah tempat pengambilan contoh telur penggerek batang padi sawah adalah 4 kecamatan $\times 4$ lokasi $=16$ tempat pengambilan contoh telur hama penggerek batang padi sawah.

Contoh telur yang diambil dari lapangan, kemudian dibawa ke laboratorium untuk inkubasi selama beberapa hari agar diperoleh data tentang parasitoid telur dan kepadatan populasi parasitoid. Setiap kelompok telur dihitung jumlah parasitoid Trichogramma sp, sehingga diketahui kepadatan populasi parasitoid pada masing-masing lokasi. Pengambilan data kelompok telur akan dilakukan sebanyak $3-4$ kali pada pertanaman padi sawah.

\section{Identifikasi Parasitoid}

Identifikasi parasitoid dewasa dilakukan berdasarkan ciri-ciri morfologis yakni bentuk antena, venasi sayap (tichia, dan remigium) dan warna imago parasitoid. Pustaka untuk identifikasi serangga parasitoid yang digunakan dalam menentukan parasitoid telur Trichogramma sp adalah Barrion \& Litsinger (1964); Gaulet \& Huber (1993); Kalshoven (1981); Pinto (1995).

\section{Pengambilan Data Primer Pada Petani}

Pengambilan data kepada petani sawah untuk mendapatkan data dan informasi mengenai serangan hama penggerek batang padi sawah. Pengambilan data kepada petani mengenai serangan dan kerusakan hama penggerek batang padi. Sebelum tim melakukan pengambilan data pada petani terlebih dahulu dibuat daftar kuesioner, sehingga memudahkan bagi tim untuk mendapatkan data primer pada petani. Pengambilan data kepada petani diantaranya serangan hama, waktu serangan yang menimbulkan kerugian, dan tindakan pengendalian. Jumlah petani responden yang dilakukan pada setiap kecamatan 5-10 petani.

Disamping itu pula dilakukan pengamatan secara visual tentang serangan hama penggerek batang padi sawah di masing-masing kecamatan Kabupaten Minahasa.

\section{Analisis Data}

Untuk mengetahui perbedaan kepadatan populasi parasitoid parasitoid Trichogramma sp dilakukan analisis secara deskriptif.

\section{HASIL DAN PEMBAHASAN}

\section{Studi Karakter Morfologi Parasitoid Telur Trichogramma sp.}

Hasil pemeliharaan telur-telur hama penggerek batang padi sawah di laboratorium telah diperoleh jenis parasitoid Trichogramma sp. Jenis parasitoid Trichogramma sp ditemukan pada semua lokasi pengambilan contoh. Dari hasil pengamatan karakter morfologi di wilayah Langowan, Tompaso, Kakas, dan Tondano ternyata mempunyai kesamaan karakter morfologi, ukuran tubuh serangga parasitoid dewasa berukuran kecil 0,4-0,5 cm, berwarna hitam, antenna betina berbentuk gada, berbulu pendek dan tumbuh jarang (hampir tidak berbulu), antenna jantan bentuk lurus dan banyak ditumbuhi bulu/rambut-rambut, antenna 
mempunyai tujuh segmen, tarsi terdiri dari tiga segmen, mata berwarna merah dan toraks berwarna hitam. Sayap depan maupun sayap belakang mempunyai rumbai-rumbai yang agak panjang dan terdapat bulu-bulu halus yang tersusun dalam garis-garis teratur bentangan sayap kurang lebih $0,6 \mathrm{~cm}$.

Dari segi karakter morfologi parasitoid Trichogramma sp yang ditemukan di Langowan, Tompaso, dan Kakas adalah sama. Jenis parasitoid Trichogramma sp tersebut mampu beradaptasi pada keempat lokasi penelitian sebagai tempat pengambilan contoh telur hama penggerek batang padi sawah. Sebaliknya terdapat jenis parasitoid yang memarasit telur hama hanya ditemukan pada tempat tertentu, sehingga agak sulit untuk dikembangkan dalam teknik pengendalian hayati seperti melakukan introduksi parasitoid. Simboh (2009) melaporkan bahwa parasitoid Trichogramma sp memarasit telur-telur hama penggerek batang padi sawah di Kabupaten Minahasa.

\section{Kelimpahan Populasi Parasitoid Telur Trichogramma sp.}

Hasil koleksi kelompok telur hama penggerek batang padi sawah yang diambil dari wilayah Langowan, Tompaso, Kakas dan Tondano, kemudian diinkubasi di laboratorium selama kurang 5 -6 hari telah muncul parasitoid Trichogramma sp. Kelimpahan populasi parasitoid yang muncul untuk keempat lokasi penelitian dengan total 322 ekor yang selengkapnya seperti terlihat pada Tabel 1.

Berdasarkan data pada Tabel 1 menunjukkan terdapat perbedaan populasi Trichogramma sp. yang muncul pada kelompok telur penggerek batang padi sawah di masingmasing lokasi pengambilan contoh. Populasi parasitoid Trichogramma sp. tertingggi ditemukan di wilayah Langowan berjumlah 115, kemudian diikuti berturut-turut Kakas 86, Tompaso 64, dan Tondano 57.

Adanya perbedaan populasi parasitoid Trichogramm sp. yang terjadi pada ekosistem tanaman padi sawah di lokasi pengambilan contoh disebabkan oleh berbagai hal; seperti faktor fisik dan biologis, juga teknik budidaya yang dilakukan oleh petani seperti di Langowan dan Kakas yang melakukan penanaman padi sawah yang tidak serentak (hal ini sesuai dengan hasil observasi dan juga wawancara dengan petani di kedua lokasi tersebut) sehingga diperkirakan parasitoid melakukan migrasi atau mengikuti perpindahan dari hama penggerek padi dari sawah yang satu ke sawah yang lainnya. Perbedaan kepadatan populasi kelompok telur penggerek batang padi di kedua lokasi ini yaitu; Langowan (25 kelompok telur) dan Kakas (21 kelompok telur) lebih padat dibandingkan di Tompaso (19 kelompok telur) dan Tondano (18 kelompok telur), sedangkan total keseluruhan kelompok telur disemuah lokasi pengamatan mencapai 83 kelompok telur (Tabel 2). Jadi dapat dipahami bahwa jumlah kelompok telur hama penggerek batang padi berkorelasi dengan jumlah parasitoid Trichogramma sp yang ditemukan pada masing-masing lokasi.

Tingginya kepadatan kelompok telur penggerk batang padi di Langowan dan Kakas akan menarik atau mempengaruhi parasitoid Trichogramma sp. untuk meletakan telurnya pada kelompok telur tersebut. Sedangkan kepadatan kelompok telur penggerek batang padi yang rendah di Tompaso dan Tondano akan membut partasitoid memerlukan waktu untuk mencari kelompok telur.

Tabel 1. Kelimpahan Populasi Parasitiod Telur Trichogramm sp.

(Table 1. Population Abundance Parasitiod Eggs Trichogramm sp.)

\begin{tabular}{lcc}
\hline & Lokasi & Populasi Trichograma spp \\
\hline Langowan & 115 \\
Tompaso & & 64 \\
Kakas & & 86 \\
Tondano & 57 \\
\hline & Total & 322 \\
\hline
\end{tabular}


Walaupun demikian tingginya populasi parasitoid Trichogramma sp. di wilayah Langowan dan Kakas bukan berarti sudah mampu menekkan populasi hama penggerek batang padi di kedua lokasi ini, karena untuk dapat menekan populasi hama diperlukan berbagai faktor, selain sifat atau kemampuna dari parasitoid itu sendiri, juga faktor penting adalah keterpaduan dengan faktor-faktor pembatas lainnya.

Selain itu pula faktor pestisida yang ikut berperan dalam kelimpahan populasi parasitoid Trichogramma sp, mungkin adanya perbedaan populasi parasitoid di masing-masing lokasi pengambilan contoh karena adanya perbedaan aplikasi pesitisda dan jenis pestisida yang digunakan pada tanaman padi sawah. Sembel dkk (2000) melaporkan bahwa petani tanaman pangan termasuk tanaman padi sawah untuk mengendalikan hama petani menggunakan pestisida. Data mengenai kepadatan populasi kelompok hama penggerek batang padi sawah pada setiap lokasi pengambilan contoh dapat disajikan pada Tabel 2.

Sebagaimana yang tercatum dalam Tabel 2 bahwa jumlah kelompok telur hama penggerek batang yang tertinggi ditemukan di Langowan, dan terendah di Tondano. Meskipun tidak dilakukan pengamatan terhadap populasi imago, diduga adanya perbedaan populasi kelompok telur dimungkinkan adanya populasi imago yang cukup tinggi. Di samping itu pula adanya interaksi interspecifik di antara populasi serangga yang ada di masing-masing lokasi pengambilan contoh. Sudah tentu bila terjadi cukup kuat kompotesi interspecifik mungkin populasi hama penggerek batang padi untuk meletakkan telurnya menjadi rendah.

\section{Persentase Serangan Hama Penggerek Batang Padi Sawah}

Persentase serangan pengerek batang padi sawah berbeda-beda diantara masing-masing lokasi studi. Rata-rata persentase serangan pada seluruh lokasi pengamatan mencapai 3,51\%. Wilayah Langowan merupakan persentase tertinggi serangan penggerek batang padi yang mencapai $4,53 \%$, kemudian diikuti berturut-turut Kakas $4,24 \%$, Tompaso $3,40 \%$, dan yang terendah Tondana hanya mencapai 2,71\% (Tabel 3).

Tabel 2. Kepadatan Populasi Kelompok Telur Penggerek Batang Padi Sawah (Table 2. The Population density of Rice Stem Borer Eggs)

\begin{tabular}{lcc}
\hline & Lokasi & Populasi telur (kelompok) \\
\hline Langowan & & 25 \\
Kakas & & 21 \\
Tompaso & & 19 \\
Tondano & Total & 18 \\
\hline & & 83 \\
\hline
\end{tabular}

Tabel 3. Persentase Serangan Pengerek Batang Padi Sawah

(Table 3. Percentage of Rice Stem Attacks Winches)

\begin{tabular}{lcc}
\hline & Lokasi & Persentase serangan (\%) \\
\hline Langowan & & 4,53 \\
Kakas & & 4,24 \\
Tompaso & & 3,40 \\
Tondano & & 2,71 \\
\hline & Total & 14,88 \\
& Rata-rata & 3,51 \\
\hline
\end{tabular}


Perbedaan persentase serangan penggerek batang padi ini menunjukkan ada berbagai aspek yang berperan. Seperti yang sudah diketahui selain parasitoid Trichograma sp., yang memarasit telur penggerek batang padi sawah di Sulawasi Utara, juga terdapat parasitioid lainnya yaitu; Telenomus sp. dan Tetrastichus sp. kedua jenis parasitoid ini populasinya cukup tinggi ditemukan memarasit telur penggerek batang padi sawah di Tompaso dan Tondano dibandingkan di lokasi Langowan dan Kakas, walaupun populasi parasitoid Trichogramma sp. di kedua lokasi ini cukup tinggi. Selain itu juga faktor lain yang dapat menekan hama penggerek batang padi sawah adalah predator dan patogen, yang dengan demikian dapat mempengaruhi tingkat serangan hama.

\section{KESIMPULAN DAN SARAN}

\section{Kesimpulan}

1. Karakter morfologi parasitoid telur Trichogramam sp. yang ditemukan di wilayah Langowan, Tompaso, Kakas, dan Tondano mempunyai kesamaan morfologi; tubuh serangga dewasa berukuran kecil 0,4$0,5 \mathrm{~cm}$, antena betina berbentuk gada, berbulu pendek dan tumbuh jarang, antenna jantan bentuk lurus dan banyak ditumbuhi bulu/rambut-rambut, antenna mempunyai tuju segmen, tarsi terdiri dari tiga segmen, mata berwarna merah dan toraks berwarna hitam, sayap belakang mempunyai rumbairumbai agak panjang dan bulu-bulu halus, dan sayap berukuran kurang lebih $0,6 \mathrm{~cm}$.

2. Kelimpahan populasi telur parasitoid Trichogramma sp. tertinggi di wilayah Langowan (115), kemudian diikuti Kakas (86), Tompaso (64), dan Tondano (57).

3. Persentase serangan penggerek batang padi sawah tertinggi di wilayah Langowan $(4,53 \%)$, kemudian diikuti Kakas $(4,24 \%)$, Tompaso (3,40\%), dan Tondano (2,71\%).

\section{Saran}

Untuk menjaga kelangsungan atau kelestarian musuh alami secara umum termasuk parasitoid Trichograma sp. dalam menekan atau menjaga keseimbangan populasi penggerek batang padi pada tingkat yang tidak menyebabkan kerusakan ekonomi maka diperlukan pengaturan frekwensi penggunaan pestisida yang bijaksana. Selain itu diperlukan pemantauan atau monitoring keberadaan musuh-musuh alami hama tanaman padi sawah yang terencana.

\section{DAFTAR PUSTAKA}

Abdul, F., Hamka dan Syafar, 2010. Respons Beberpa Varietas Unggul Baru Padi Sawah Terhadap Serangan Hama Utama di Sulawesi Selatan. Prosiding Seminar IImiah dan Pertemuan Tahunan PEI XX Komisaris Daerah Sulawesi Selatan. Makasar.

Anonim, 1991. Musuh Alami Organisme Pengganggu Tanaman Padi Sawah. Direktorat Jenderal Pertanian Tanaman Pangan. Jakarta.

Anonim, 2008. Laporan Tahunan. Dinas Pertanian Tanaman Pangan dan Peternakan Sulawesi Utara. Manado.

2011. Pengendalian Hama penggerek Batang Padi Melalui Konservasi Parasitoid.

http://bali.litbang.deptan.go.id/ind/index.ph p?option=com

Hawkins, H. H., H.V. Cornell and Hochberg. 1997. Predator, Parasitoid, and Patogen as Mortality Agens in Phytophagous Insect Population. Ecol Soc. Amer 78 () 2145 2152.

Kalshoven, L.G.E. 1981. The Pests of Crops In Indonesia. PT. Ichtiar Baru Van Hoeve. Jakarta.

Melina., A Nurarinaty, 1997. Pelepasan Parasitoid Trichogramma sp (Hymenoptera; Trichogrammatidae). Sebagai Agensia Pengendalian Hayati Penggerek Batang Padi di Sulawesi Selatan. Pengelolaan Serangga Berkelanjutan. Perhimpunan 
Entomologi Indonesia. Universitas Padjadjaran Bandung.

Rondonuwu, D. dan J. Rimbing. 2000. Keanakeragaman Serangga Parasitoid dan Populasinya Pada Serangga Hama Tanaman Padi Sawah di Kabupaten Minahasa. Media Publikasi IImu Pertanian. Eugenia. Fakultas Pertanian Unsrat. Manado.

Sembel, D.T., J. Rimbing, dan M. Ratulangi., M. Meray. 2000. Pemantauan dan Peramalan Organisme Pengganggu Tanaman Pangan di Sulawesi Utara. Fakultas Pertanian Unsrat Manado.
Simboh, J.S. 2009. Kenekargaman Jenis Parasitoid Telur pada Hama Penggerek Batang Padi Sawah Scirpophaga spp di Kabupaten Minahasa. Fakultas Pertanian, Universitas Sam Ratulangi. Manado.

Taroreh, D., V. Memah dan J. Rimbing, 1993. Komposisi Parasitoid Telur Hama Penggerek Batang Padi di Kabupaten Minahasa. Fakultas Pertanian Unsrat. 